\title{
Auctioning off Prizes for Agricultural Product Flow under a Policy of Minimum Prices $^{*}$
}

\author{
Wilson da Cruz Vieira ${ }^{\dagger}$
}

\author{
Contents: 1. Introduction; 2. Program for Product Flow: Description and Data; 3. Model; 4. Results; \\ 5. Concluding comments. \\ Keywords: Auctions, Agricultural Policy, Price Support, Brazil. \\ JEL Code: $\quad$ D44, Q11, Q18.
}

In this article, we analyze the use of descending clock auctions in the implementation of a minimum pricing policy. This type of auction has been used by the Brazilian government policy of support for agricultural prices. We propose a clock auction model along the lines used by the Brazilian government and derive its main implications. Based on data from auctions already held and implications of the theoretical model, we conclude that the following factors are crucial to minimize the costs of implementing a minimum price policy via auctions: the choice of product to be auctioned, amount auctioned, reserve price (maximum prize), and auction rules.

Analisa-se, neste artigo, o uso de leilões-relógio descendentes na implementação de uma política de preços mínimos. Este tipo de leilão tem sido utilizado pelo governo brasileiro em sua política de garantia de preços mínimos. Propõe-se um modelo de leilão-relógio nos moldes utilizado pelo governo brasileiro e derivam-se suas principais implicações. Baseado em dados de leilões já realizados e nas implicações do modelo teórico, conclui-se que os seguintes fatores são cruciais para minimizar os custos de implementação de uma política de preços mínimos via leilões: a escolha do produto a ser leiloado, a quantidade leiloada, o preço de reserva (prêmio máximo) $e$ as regras do leilão.

\section{INTRODUCTION}

The auctions are fairly common mechanisms to allocate goods and have been used for centuries. They have been used to sell goods as diverse as antiques, art objects, fresh flowers, tobacco, fish, gold, real estate properties, securities, and natural resource exploitation rights. Cassady (1967) provides a relatively complete list of goods that are sold through auctions. Over time, the list of these goods has increased substantially. More recently, auctions have been used to allocate contracts for environmental services

\footnotetext{
*This research received support from Conselho Nacional de Desenvolvimento Científico e Tecnológico (CNPq). In addition to this institution, the author would like to thank Rafael Lima and an anonymous referee for their valuable comments and suggestions.

†Universidade Federal de Viçosa, Departamento de Economia Rural. Viçosa-MG, Brazil. Email: E-mail: wvieira@ufv.br
} 
(see, for example, Latacz-Lohmann \& Van der Hamsvoort, 1997, and Ajayi, Jack, \& Leimona, 2012), electricity supply (see, for example, Fabra, von der Fehr, \& Harbord, 2006, and Ciarreta \& Espinosa, 2010), spectrum licenses (see, for example, Grimm, Riedel, \& Wolfstetter, 2003, and Cramton \& Sujarittanonta, 2010), emission permits (see, for example, Sunnevåg, 2003, and Betz, Seifert, Cramton, \& Kerr, 2010), among others. Since 1997 auctions have also been used by the Brazilian government in its agricultural price support policy.

In Brazil, the agricultural price support policy is based on a system of guaranteed minimum prices and consists of several programs. This article focuses on the Program for Product Flow (Prêmio para Escoamento de Produto, PEP), which is implemented through a descending clock auction. This program was created in 1996 in a reformulation of the price support policy in order to give more flexibility to the policy of minimum prices in a context of fiscal resource constraints and economic liberalization.

In the PEP, public auctions are used to set a prize for agricultural product flow from a region with excess supply to another where there is shortage of this product. This prize is a subsidy (subvention) paid by the federal government to the winning bidders who agree to purchase the product by the reference price (minimum price) in a given region, directly from producers (or cooperatives), and flow it off to a previously established consumer region. Whenever there is excess supply in a given region and the market price is below the minimum price, the government announces the auction, indicating the amount of product that will be auctioned and the maximum prize that it is willing to pay. In a successful auction, producers (or cooperatives) receive the minimum price per unit of product (above the market price) and prices in the destination region tend to fall due to increased supply. Thus, the agricultural price dispersion is reduced throughout the year and market prices tend to converge to the minimum prices set by the government.

Since the inception of the PEP, various agricultural products have been included. Initially, the auctions focused on cotton, corn and wheat. Later, other products were included, such as rice, beans, soybeans, sisal, fresh milk and wine. However, in terms of volume of government spending with prizes and frequency of the auctions, the main products covered by this program are corn and wheat.

Three results have usually emerged from these auctions. First, the auction is announced by the government and is not held for lack of bidders. Second, the auction is held and the whole or only part of the amount made available for transfer between regions is acquired by the bidders and the government pays the maximum prize announced at the beginning of the auction (reserve price). Third, the total amount of the product announced by the government is acquired by the winning bidders for transfer between regions and the competition between them leads to reduction of the initial prize.

Although the auctions of the PEP have already been carried out for more than 15 years, there are no studies aiming to analyze them more deeply. ${ }^{1}$ In this article, the study concentrates on these auctions. The main objective is to propose an auction model and derive its implications in order to explain the results mentioned above. Then, based on the implications of the theoretical model and available data from auctions of the PEP already held, identify factors that are crucial to reduce the costs of implementing a minimum price policy via auctions. ${ }^{2}$

The results obtained in this article suggest that the following factors are crucial to minimize the costs of implementing a minimum price policy via auctions. First, the government should select agricultural commodities with large number of buyers and sellers; agricultural products with these characteristics tend to attract more participants to the auctions. Second, the value of the maximum prize (reserve price) must cover at least the cost of product transfer between regions and eventually allow some margin gains to bidders in order to encourage participation and/or competition between them. Third, the amount

\footnotetext{
${ }^{1}$ Most studies only describe the PEP as an instrument of the Policy on Guaranteed Minimum Price of the Brazilian government (see, for example, Bel Filho \& Bacha, 2005). The study carried out by Pereira \& Vieira (2009) is an exception, since it analyzed the auctions of the PEP, although superficially.

${ }^{2}$ Note that the analysis developed in this article (cost minimization for the auctioneer) contrasts with that typically developed in auction theory that seeks to identify auction formats that maximize the expected revenue for the auctioneer.
} 
of the product being auctioned should be based on accurate estimates of excess supply in the region of origin and excess demand in the region of destination. Fourth, the auction rule that allows the purchase of only part of the auctioned product for transfer between regions may hinder the effective implementation of the policy of minimum prices.

In the next section of this article, we describe the PEP in more detail and provide some data on the types of products auctioned and the prizes (subsidies) that the federal government has paid since the creation of this program. In the third section, we model the public auctions of the PEP, i.e., we model a descending clock auction along the lines used by the Brazilian government. The fourth section derives the implications of the clock auction model of the previous section and discusses the results. Finally, in the fifth and last section, we present some concluding comments.

\section{PROGRAM FOR PRODUCT FLOW: DESCRIPTION AND DATA}

As previously mentioned, the Program for Product Flow (PEP) aims at promoting the transfer of agricultural products from a production region to a region of consumption, following a minimum price policy. This program is implemented through public auctions where winning bidders receive a prize (subsidy) to purchase the auctioned product directly from producers (or cooperatives) and to flow it to the region of consumption. The government does not buy the product and winning bidders must purchase the product in the region of origin and allocate it in the target region to receive the prize.

This program is run by the National Supply Company (CONAB), an agency of the Ministry of Agriculture, Livestock and Food Supply (MAPA), whenever the market price of the agricultural product falls below the minimum price set by the Brazilian government. The initial prize or the maximum prize that the government is willing to pay (reserve price) is calculated by the Office of Agricultural Policy (SPA), an agency also linked to the MAPA. The amount of agricultural products to be auctioned is defined by CONAB and the SPA, based on estimates of excess supply in the region with market price below the minimum price set by the government.

The auction is announced by CONAB in advance of five days by a Specific Notice. This notice contains information such as date and time of the auction, agricultural product and quantity to be auctioned, maximum prize (reserve price), region of origin, region of destination and conditions for participating in the auction. This is accomplished through the CONAB Electronic Trading System, together with various Commodities Exchange and/or Cereals Exchange. Those willing to participate should meet the requirements of the Specific Notice and appoint a broker related to one of these Commodities Exchange and/or Cereals Exchange to make bids. In other words, the interested parties do not participate directly in the auction and are not obliged to be present during its implementation.

These auctions may have three results. First, the auction is announced by the government and is not held due to the lack of bidders. Second, the auction is held and the quantity of the product demanded for transfer between regions is less than or equal to the amount announced by the government; in this case, the auction ends and the final prize is the one announced at the start of the auction (maximum prize). Third, the auction is held and the sum of the bidders' demands for transfer between regions is greater than the quantity announced by the government; in this case, the auctioneer reduces the initial prize and the bidders announce their new demands. If excess demand at current prize continues, the prize will continue being reduced by the auctioneer until the quantity demanded by bidders is fit to the quantity supplied for transfer between regions.

There is no fixed proportion for prize reduction when there is excess demand for transfer between regions. The auctioneer can decide on this reduction in accordance with market conditions at the time of the auction. Higher excess demands may lead to higher proportional reductions of the prize, compared to smaller excess demands. The duration of the auction ranges from half an hour to a day, i.e., there is no fixed time for ending the auction. When the auction ends, the prize is defined per unit of product payable to the winning bidders. The total prize to be paid by the government to each winning bidder is proportional to its quantity demanded for transfer from the region of origin to the region of destination 
at the time of auction closing.

When the auction ends, the winning bidder must search for the producer or cooperative in the region of origin indicated in the Specific Notice to purchase the auctioned agricultural product at the minimum price set by the government. Besides the minimum price per unit of product, the winning bidder has to pay a number of taxes before receiving the prize. ${ }^{3}$ These costs include payments to the broker of the Commodities Exchange and/or Cereals Exchange, costs to identify producers (or cooperatives) willing to sell products at the minimum price, payment of taxes and fees, costs with transportation to take the product from the region of origin to the region of destination and transaction costs to market the product in the target region (if the winning bidder is a wholesaler). Therefore, it is interesting that CONAB announces the maximum prize (reserve price) in advance so that the interested parties can evaluate the profit opportunities and decide whether they will participate or not in the auction announced by the government.

The Specific Notice related to the auction of the PEP contains much more information, besides the provided above. It indicates, for example, the class/type/harvest of the agricultural product that will be auctioned and the penalties that winning bidders are subject in the case of non-fulfillment of their obligations under the PEP. Payments to producers or cooperatives in the region of origin must be made through the Banco do Brasil. Finally, CONAB is not responsible for any problems related to the quantity or quality of the product which is the object of the transaction between the winning bidder and the producer or cooperative, but it can oversee the entire operation.

Other two aspects related to the auctions of the PEP should also be mentioned. First, once the amount of the product being auctioned is estimated, CONAB can hold a single auction or conduct several auctions at intervals ranging from one week to a fortnight; in the latter case, it can supervise the evolution of prices in the regions of origin and destination and decide whether new auctions will be performed. Second, depending on the characteristics of the market, CONAB can perform auctions targeted to specific interested parties, similarly to a recent auction of corn, of which only breeders of birds, pigs, cattle, goats and sheep could participate, as well as representatives of industries of human and animal food, but not wholesalers and tradings.

Table 1 shows details of the operations of the PEP for the period 2005-2012. We considered only the main products traded via auctions in this period, i.e., wheat, corn, rice and wine. Note that, in this period, they were also held auctions of cotton, beans, fresh milk, soybeans and sisal; however, the quantities traded of these products were much smaller and/or occurred sporadically. In the case of soybeans, for example, auctions were implemented only in 2006 , when they were auctioned $5,194,575$ tons of this product. In the case of fresh milk, the auctions took place only in 2009, having been auctioned 169,500 tons of this product. Over the past three years of this period, the Brazilian government has held several auctions of sisal, having been auctioned 57,468 tons of this product in 2010, 93,619 tons in 2011 and 7,175 tons in 2012 .

Wheat and corn are by far the main products covered by the PEP in terms of both quantities auctioned and prizes paid by the government (see Table 1). Rare are the years in which there are no auctions of these products. The amounts auctioned of these products vary between years in accordance with the excess supply and excess demand between regions. In the period 2005-2012, they were auctioned $9,729,773$ tons of wheat and 21,916,242 tons of corn, and the prizes (subsidies) paid by the Brazilian government were $R \$ 1,496,378.21$ and $R \$ 1,763,167.13$, respectively. Two other important products covered by the Program for Product Flow are rice and wine whose auctions have been implemented with some regularity. In the period 2005-2012, they were auctioned 2,298,788 tons of rice and 89,734 tons of wine, and the corresponding prizes paid by the Brazilian government were $\mathrm{R} \$ 312,630.62$ and $\mathrm{R} \$ 60,987.12$, respectively.

\footnotetext{
${ }^{3}$ The winning bidder receives the award for a period of up to 5 business days after delivering to CONAB the documentation evidencing the purchase of the product in the region of origin and its allocation in the target region, as determined in the Specific Notice.
} 


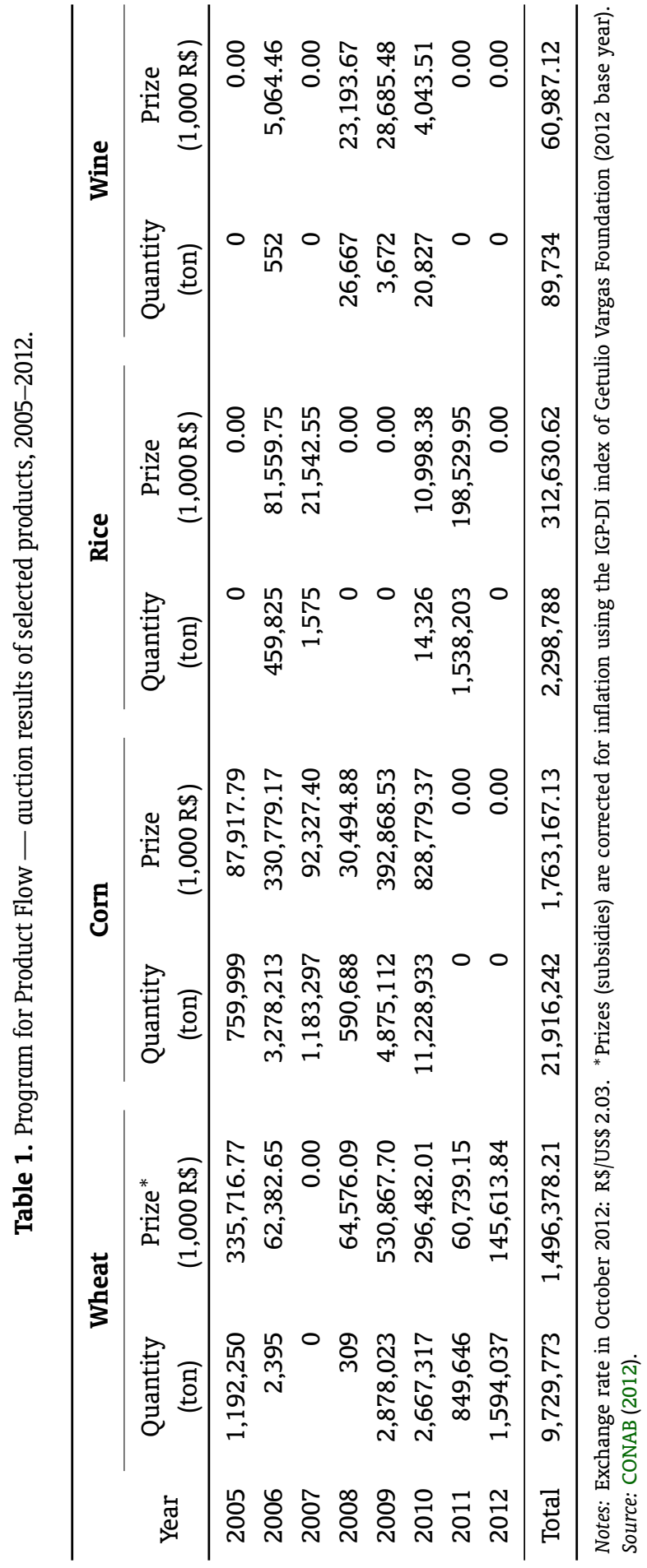


Table 2 shows the results of six auctions of the PEP implemented in 2005. This is a small sample to illustrate the results that have emerged from these auctions. Note that these auctions are implemented throughout the year and that the quantities of agricultural products made available by the government vary between auctions and for the same product. Another aspect that should be highlighted is that the government prioritizes the region of origin when deciding for implementing the auction. This region of origin, in general, is a specific state, while the destination region, in general, is represented by some states, a region of the country or the country itself.

Table 2. Results of specific auctions of the Program for Product Flow, 2005

\begin{tabular}{|c|c|c|c|c|c|c|c|}
\hline \multirow{2}{*}{ Month } & \multirow{2}{*}{ Product } & \multirow{2}{*}{ Origin } & \multirow{2}{*}{ Destination } & \multicolumn{2}{|c|}{ Quantity (1,000 Kg) } & \multicolumn{2}{|c|}{ Prize $(\mathrm{R} \$ / \mathrm{Kg})$} \\
\hline & & & & Initial & Auctioned & Initial & Final \\
\hline January & Wheat & PR & $\mathrm{NO} / \mathrm{NE}$ & 60,000 & 0 & 0.000 & 0.000 \\
\hline January & Wheat & RS & $\mathrm{NO} / \mathrm{NE}$ & 310,000 & 97,000 & 0.132 & 0.132 \\
\hline February & Corn & BA & $\mathrm{NO} / \mathrm{NE}$ & 16,000 & 16,000 & 0.054 & 0.041 \\
\hline September & Corn & MT & $\mathrm{NE}$ & 56,000 & 30,410 & 0.097 & 0.097 \\
\hline February & Cotton & MT & BR & 22,350 & 22,350 & 0.420 & 0.420 \\
\hline April & Cotton & SP & BR & 7,500 & 3,199 & 0.336 & 0.336 \\
\hline
\end{tabular}

Source: CONAB (2012).

One of the two wheat auctions held in January 2005 had no interested bidders; the Brazilian government has provided 60,000 tons of this product for transfer between regions, being the state of Paraná (South region) the region of origin and the regions North and Northeast, the region of destination. In another auction of wheat, 310,000 tons were made available by the government and auctioned only 97,000 tons at the maximum prize of $\mathrm{R} \$ 0.132 / \mathrm{Kg}$. A similar situation occurred with the corn in a September 2005 auction, in which 56,000 tons were offered and were auctioned only 30,410 tons at the maximum prize of R\$0.097/Kg. Table 2 shows also two situations, corn and cotton auctions held in February 2005, when they were auctioned off all the amounts made available by the government and the competition between bidders led to the reduction of the maximum prizes, being this reduction more pronounced in the case of the cotton.

\section{MODEL}

The theoretical model developed in this section takes into account aspects of the Program for Product Flow (PEP) of the Brazilian government, mainly the definitions of the initial prize (maximum prize) and the amount of agricultural product to be auctioned as part of a minimum price policy. Figure 1 shows the operation of the program (market conditions). For the purpose of simplification, only two regions with a large number of buyers and sellers of a homogeneous agricultural product were considered: Region 1 (region of origin) and region 2 (region of destination). The analysis developed below is not affected if one region of origin and more than one region of destination are considered.

In region 1 (left side of Figure 1 ), $P_{1}$ and $Q_{1}$ refer to the price and quantity of equilibrium resulting from the interaction between the curves of supply $\left(S_{1}\right)$ and demand $\left(D_{1}\right)$ of the agricultural product under analysis. In turn, $P_{2}$ and $Q_{2}$ refer to the price and quantity of equilibrium resulting from the interaction between the curves of supply $\left(S_{2}\right)$ and demand $\left(D_{2}\right)$ of the product in region 2 (right side of Figure 1). We assume throughout this article that the supply curves are positively sloped and the demand curves are negatively sloped. Let us assume that the government establishes a minimum price per unit of product equal to $P_{\mathrm{I}}$. Note that, at this level of price, there is excess supply in region 1 equal to the difference $b-a$ and excess demand in region 2 equal to the difference $d-c$. Note that this excess 
Figure 1. Market conditions in two different regions.

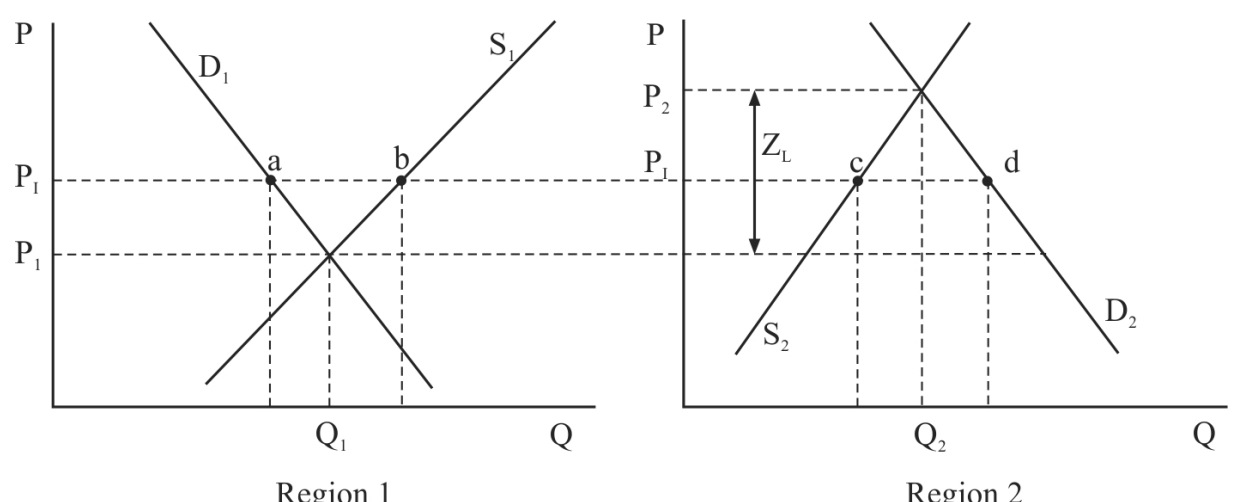

supply in region 1 may differ from excess demand in region 2; however, we assume initially that they are equal, i.e., $b-a=d-c=K{ }^{4}$

The government promotes a public auction to favor product flow from region 1 (region of origin) to region 2 (region of destination). In this auction, the government defines both the initial prize (reserve price), which is the maximum prize per unit of product that it is willing to pay for the product flow from region 1 to region 2, as well as the amount to be auctioned. Figure 1 clearly shows that the quantity to be auctioned is equal to $K$. In the case of maximum prize, the definition of its value is not as trivial and may affect the government spending, with direct impact on the cost of the PEP. From the social standpoint, it is important to minimize these costs.

Regardless of the realization of the auction, there are transfer costs (transportation costs, fees, taxes, etc.) that need to be covered so that the product can flow from region 1 to region 2 . Assuming that there is arbitrage by market participants between regions 1 and 2, these transfer costs for product flow between these two regions are equal to the difference between their market prices, namely, $P_{2}-P_{1}=$ $Z_{\mathrm{L}}$ (see Figure 1). Thus, the prize that emerges at the close of the auction should cover at least the usual transfer costs besides the cost of brokerage, since participants have to pay a broker related to a Commodities Exchange and/or Cereals Exchange to represent them during the auction.

Considering that not all markets for agricultural products are perfectly competitive markets, and that the prize (subsidy) offered by the government should cover at least the transfer cost plus cost of brokerage, the maximum prize (reserve price) per unit of product set by the government must be greater than $Z_{\mathrm{L}}$. The following question is raised: how much greater must this value be? The official documents of the Brazilian government on the auctions of the PEP do not clearly state the criteria used to calculate the maximum prize. Thus, in this article we consider that the maximum prize, denoted by $Z_{\mathrm{H}}$, is equal to $Z_{\mathrm{L}}$, plus $10 \%$ of this value (see examples given below). Thus, the prize that emerges at the close of the auction shall be in the interval $Z \in\left(Z_{\mathrm{L}}, Z_{\mathrm{H}}\right]^{5}$

After the definition of the maximum prize (reserve price) and the amount of agricultural product to be auctioned, we are ready to model the auction. Public auctions of the PEP are classified as of multiple units (homogeneous product) and uniform price. These auctions are conducted via electronic systems. Therefore, they are also known as clock auctions, though of the descending type, since the

\footnotetext{
${ }^{4}$ If differences are observed between the excess supply in the region of origin and excess demand in the region of destination, the government may consider more than one region of origin and more than one region of destination to adjust the quantities supplied and demanded at minimum price and establishes different prizes for pairs of distinct regions.

${ }^{5}$ The government should expect to pay a prize greater than $Z_{\mathrm{L}}$ because no bidder will participate in an auction unless he expects to get a positive payoff. The $K Z_{\mathrm{L}}$ value represents the minimum expenditure (benchmark) of government in each auction considering a situation of perfect competition.
} 
prize decreases after each round of the auction. These auctions can be modeled as sealed-bid uniformprice auctions or through a dynamic approach using backward induction. According to Milgrom (2004, p.284), depending on the assumptions adopted, both modelings show strategic equivalence.

We decided to use a dynamic approach of a multi-unit uniform-price auction (descending clock auction). Milgrom (2004, p.284-287) presents a basic model of clock auction and illustrates the use of backward induction based on a simple symmetric model. An alternative model of multi-unit uniform-price clock auction is used by Ausubel \& Schwartz (1999). These authors model the auction as an extensive game with perfect information and alternate bids. In this article, auctions are modeled as an extensive game with perfect information and simultaneous bids, which is the form of implementation of the auctions of the PEP.

Before the start of the auction of the PEP, participants are informed about the amount of agricultural product to be auctioned (which should be transferred to the destination region by the winning bidders) and the maximum prize (reserve price). After the auction starts, the only public information is the current prize that is placed into digital clock by the auctioneer (in this case, CONAB), i.e., the displayed prize summarizes all public information at any time during the auction. This is a desirable aspect of the auction, since, according to Milgrom (2004), it reduces the chances of collusion between participants. In each round, the auctioneer lowers the prize decrementally whenever the amount that bidders are willing to transfer exceeds supply announced by the government. The auction ends when the sum of the amounts that winning bidders wish to flow to the region of destination is greater than or equal to the quantity supplied.

The clock auction model presented below is an adaptation of the basic model of clock auction developed by Milgrom (2004) already mentioned. Instead of an ascending auction with fixed supply, we consider a descending auction with fixed demand (amount of agricultural product that should be placed in the region of destination). We also adjusted the payoff function of typical bidders and noted that the analysis is not done in isolation, i.e., focusing only on the auction itself, but it considers the effects of the auction results in implementing the minimum price policy.

Let us consider a descending clock auction with $N$ bidders and the amount $K$ of a perfectly divisible product. If the total amount $K$ is auctioned and the winning bidder $j$ agrees to transfer $q$ units from the region of origin to the region of destination at prize $Z$, then its payoff function is given by $\pi^{j}=$ $Z q-C^{j}(q)+\left(P_{\mathrm{F}}-P_{\mathrm{I}}\right) q$, where $C^{j}(q)$ is the transfer cost function and $P_{\mathrm{F}}$ is the final price in the region of destination after the allocation of the amount of the product auctioned in this region. It is assumed that the function $C^{j}(q)$ is continuous and strictly convex and that the winning bidder $j$ buys the product in the region of origin at the minimum price established by the government, $P_{\mathrm{I}}$, and allocates it in the region of destination. Note that, if excess supply in the region of origin is equal to excess demand in the region of destination at the minimum price established by the government, and both are equal to $K$, then $P_{\mathrm{F}}=P_{\mathrm{I}}$ if all amount $K$ is auctioned and transferred to the region of destination; otherwise, in general, $P_{\mathrm{F}} \neq P_{\mathrm{I}}$. Note also that the price $P_{\mathrm{F}}$ varies with the total amount of product placed in the target region and therefore it depends on the strategies adopted by the auction's participants.

The transfer function of the product from the region of origin to the region of destination associated to the payoff function of the winning bidder $j$ is given by

$$
q^{* j}(Z)=\underset{x \in R_{+}}{\arg \max }\left\{Z x-C^{j}(x)+\left(P_{\mathrm{F}}-P_{\mathrm{I}}\right) x\right\} .
$$

If the sum of the bidders' demands for product transfer between regions is lower than the total amount $K$ announced by the government, then the auction ends in the first round at the initial prize $Z_{\mathrm{H}}$. In this case, the payoff of the winning bidder $j$ changes to $\pi^{j}=Z_{\mathrm{H}} q-C^{j}(q)+\left(P_{\mathrm{F}}-P_{\mathrm{I}}\right) q$. Note that, according to market conditions, especially if excess supply differs from excess demand at the minimum price established by the government and auction rule allows to transfer less than $K$, payoffs may have distinct values, which may lead bidders to adopt distinct bid functions (strategies) aiming to take advantage of it. 
The clock starts at some maximum prize $Z_{\mathrm{H}}$ (reserve price) and decreases at small increments round after round. Each bidder announces the amount of the product he wishes to flow from the region of origin to the region of destination at current prize. If, in the first round, the sum of the bidders' demands for product transfer between regions is less than or equal to the amount $K$ announced by the government, the auction ends, and the current prize is the maximum prize $Z_{\mathrm{H}}$. Otherwise, the auction ends when the sum of the bidders' demands for product transfer between regions is greater than or equal to the total amount $K$ announced by the government. When the auction ends, the prize per unit of product that the winning bidder will receive after the transfer of the product is equal to $Z_{\mathrm{H}}$, in the first case, and $Z_{\mathrm{L}}<Z<Z_{\mathrm{H}}$, the current price shown on the clock, in the second case.

Given the market conditions of the agricultural product in the regions of origin and destination and the rules of the auction, bidders define their strategies. Thus, bidders will not participate in the auction when the maximum prize is lower than the total cost of transfer (including brokerage cost) per unit of product from the region of origin to the region of destination. Otherwise, each bidder will use the following non-decreasing strategy, $q:\left(Z_{\mathrm{L}}, Z_{\mathrm{H}}\right] \rightarrow(0, K]$, which maps possible prizes in the interval $\left(Z_{\mathrm{L}}, Z_{\mathrm{H}}\right]$ at bids of amounts of the agricultural product in the interval $(0, K]$. Since those interested in participating in the auction must pay a broker related to the Commodities Exchange and/or Cereals Exchange to make bids, it is assumed that they will attempt to acquire a strictly positive amount $q>0$ to avoid negative payment in the end of the auction.

\section{RESULTS}

The descending clock auction model described in the previous section is an extensive-form game with perfect information and simultaneous bids. Since it is an extensive-form game with finite horizon, it is possible to use backward induction to find its possible equilibria (Osborne \& Rubinstein, 1994). The strategies adopted by bidders (bid functions) are continuous and represented by the non-decreasing function $q(Z)$ that maps prizes at bids of amounts of product to be transferred from one region to another. In the case of the auctions of the PEP, the Brazilian government announces in advance the total amount of the agricultural product to be transferred from the region of origin to the region of destination and the maximum prize that it is willing to pay per unit of product transferred.

Before presenting and discussing the equilibria of the game of the descending clock auction described in the previous section, we will consider the following additional assumptions.

Assumption 1. In the homogeneous agricultural product market under analysis, there is a large number of buyers and sellers and arbitrage occurs only between the region of origin (region 1) and the region of destination (region 2), i.e., there is no influence from other regions on the prices and quantities of equilibrium in these two regions.

Assumption 1 avoids complications in the analysis due to considerations that other regions may affect the prices and quantities of equilibrium of the agricultural product in the regions 1 and 2 . This is a simplification which aims to facilitate the analysis. As previously mentioned, it is easy to extend the analysis to consider, for example, one region of destination and two regions of origin. In this case, after the calculations of excess supply/excess demand in the three regions at the minimum price set by the government, the amounts to be transferred and the maximum prizes between pairs of regions would be established. The auctions would be implemented for pairs of regions.

Assumption 2. The auction ends immediately if the sum of the bidders' demands for product transfer between regions (aggregated transfer function) at the maximum prize is lower than or equal to the amount of the agricultural product $K$ made available by the government, and $M, 0<M \leq K$, is the minimum amount to be transferred.

Auctions of the PEP implemented by CONAB ends immediately when the sum of the bidders' demands at the maximum prize is lower than or equal to the amount of agricultural product made available by 
the government for transfer between regions. As already mentioned, bidders can take advantage of this auction rule to increase their gains.

The main results of this article are derived from the clock auction model described in the previous section and the assumptions above. In the first result (Proposition 1), weakly dominated strategies are identified and eliminated. This first result is an adaptation of the Theorem 7.6 presented in Milgrom (2004, p.286) in order to consider a descending clock auction with fixed demand. In the second result (Proposition 2), it is assumed that bidders are symmetric, and the symmetric Nash equilibria of the clock auction game are characterized. Proposition 2 was inspired by the Theorem 7.7 of Milgrom (2004, p.286-287), and the novelty is that we explicitly considered the characteristics of the auctions of the PEP implemented by the Brazilian government.

Proposition 1. Suppose that a descending clock auction with fixed demand $K>0$ and prizes in the interval $0<Z<\infty$ is implemented with $N \geq 2$ bidders. Let $q(Z)$ be any strategy (bid function) used by a bidder and let us assume that $q^{\#}(Z)=\min \left\{q(Z), q^{*}(Z)\right\}$. If $q \neq q^{\#}$, then $q^{\#}$ dominates $q$ weakly.

Proof. Let us assume that $q \neq q^{\#}$. Observe that these strategies lead to different prizes in the end of the auction. Therefore, it is sufficient to show that whenever the results corresponding to these strategies are different, $q^{\#}$ generates a payoff strictly higher than $q$. Let us assume that the results $(Z, q(Z))$ and $\left(Z^{\#}, q^{\#}\left(Z^{\#}\right)\right)$, arising from the adoption of the strategies $q$ and $q^{\#}$, respectively, are different. Given that $q^{\#} \leq q$ for any level of prize, then $Z^{\#}>Z$. By the definition of $q^{*}$ and the fact that $Z^{\#}$ is not a market clearing prize for the transfer function $q$, then $\left(Z^{\#}, q^{\#}\left(Z^{\#}\right)\right)=\left(Z^{\#}, q^{*}\left(Z^{\#}\right)\right)$. Note that a bidder prefers $\left(Z^{\#}, q^{*}\left(Z^{\#}\right)\right)$ rather than the result $\left(Z, q^{*}(Z)\right)$ because both are prize-taking transfer functions and the latter result has a lower prize. Observe that the result $\left(Z, q^{*}(Z)\right)$ is weakly more profitable for a bidder than $(Z, q(Z))$. Thus, bidders prefer $\left(Z^{\#}, q^{\#}\left(Z^{\#}\right)\right)$ rather than $(Z, q(Z))$.

For the next proposition, we assume that bidders are symmetric and therefore adopt the same bidding strategy $q$ and have the same transfer cost function $C(q)$, which is assumed to be strictly convex and continuously differentiable. Backward induction will be used to identify the equilibria of the descending clock auction game. Given the symmetry assumption in this game, it is assumed that the parameters $M$ and $K, M \leq K$, previously defined, are equal, respectively, to the following expressions: $M=m N$ and $K=k N$, with $m=k$, only if $M=K$. In this case $K$ refers to the excess demand in the region of destination at the minimum price set by the government, which is equal or different to the excess supply in the region of origin. The payoff functions $\pi$ will be indexed according to the amount of agricultural product auctioned, i.e., $M$ or $K$.

Proposition 2. Suppose that a descending clock auction with fixed demand $K>0$ and finite maximum prize $\left(Z_{H}>0\right)$ is implemented with any number $N$ of bidders.

(i) If the marginal cost of transfer of the agricultural product from the region of origin to the region of destination $C^{\prime}(q)$ is such that $C^{\prime}(q)>Z_{H}$, then the strategy $q\left(Z_{H}\right)=0$ is a symmetric Nash equilibrium of the descending clock auction game;

(ii) If the marginal cost of transfer is in the interval $Z_{L}<C^{\prime}(q)<Z_{H}$, the auction rule allows transferring a quantity $M, 0<M \leq K$, and the payoff of bidders is such that $\pi_{M}>\pi_{K}$, then the strategy $q\left(Z_{H}\right)=$ $\min \left\{m, q^{*}(Z)\right\}$ is a symmetric Nash equilibrium of the descending clock auction game; otherwise, i.e., if the payoff of bidders is such that $\pi_{M}<\pi_{K}$, then the strategy $q\left(Z_{H}\right)=\min \left\{k, q^{*}(Z)\right\}$ is a symmetric Nash equilibrium of the descending clock auction game.

Proof. (i) This is an obvious result, since if the maximum prize does not cover the marginal costs of transfer of the agricultural product from the region of origin to the region of destination, no bidder will be interested in participating in the auction; thus, the auction is not effectively implemented due to lack of bidders; 
(ii) If each bidder adopts the strategy indicated, then no bidder will want to transfer more than $m$. Therefore, the bids are immediately interrupted at the maximum prize $Z_{\mathrm{H}}$ and each bidder will be committed to transfer $\min \left\{m, q^{*}(Z)\right\}$ units from the region of origin to the region of destination at prize $Z_{\mathrm{H}}$. Among the possibilities of deviation, it is observed that purchasing an amount smaller than $m$ for subsequent transfer is not feasible because of Assumption 2. On the other hand, if there is any profitable deviation, it must be such that the deviator accepts transferring $q^{\#}>m \leq k$ at prize $Z_{\mathrm{H}}$ only if $q^{\#}=k$ provided that $\pi_{M}<\pi_{K}$. For $q^{\#}>k$ and some prize $Z^{\#}, Z_{\mathrm{L}}<Z^{\#}<Z_{\mathrm{H}}$, we can use the Proposition 1 and assume, without generality loss, that $q^{\#} \leq q^{*}$. These inequalities imply that at the prize $Z^{\#}$, the $N-1$ bidders who do not deviate will acquire each one of them for transfer between regions $\min \left\{k, q^{*}(Z)\right\}=k$. Therefore, the total amount of the product purchased for transfer is $q^{\#}+(N-1) k>K$, which demonstrates that the market cannot clear.

When the excess demand in the region of destination is less than the excess supply in the region of origin at the reference price (minimum price), and assuming that the amount $K$ is equal to the excess supply, the quantity of the agricultural product auctioned is often lower than the total amount provided by the government. If the excess demand is greater than the excess supply at the minimum price set by the government, then the entire amount $K$ (equal to the excess supply) is auctioned off at the maximum prize or value less than the maximum prize if competition among bidders leads to the reduction of this prize. Note also that, if the excess demand is less than the excess supply, the gains of the bidders (payoffs) may be higher if they demand an amount to transfer between regions smaller than the quantity $K$ provided by the government at the beginning of the auction. The following examples illustrate these two situations.

Example 1. Consider the following simple market model of a homogeneous agricultural product. In region 1 (region of origin), demand is represented by the function $P=7-Q$ and supply is represented by the function $P=-3+Q$, where $P$ and $Q$ denote price and quantity, respectively. In region 2 (region of destination), demand is represented by the function $P=11-Q$ and supply is represented by the function $P=-1+Q$. The ordered pairs $\left(Q_{1}^{*}, P_{1}^{*}\right)=(5,2)$ and $\left(Q_{2}^{*}, P_{2}^{*}\right)=(6,5)$ denote quantities and prices of equilibrium in the regions 1 and 2, respectively. Suppose that the government set a minimum price per unit of product equal to 4 . At this intervention price, excess supply in region 1 is equal to 4 and excess demand in region 2 is equal to 2 . Suppose further that the government announces the maximum prize $Z_{\mathrm{H}}=3.3$ and that the amount to be transferred from region 1 to region 2 is in the interval $3.5=M \leq 4=K$. In this example, bidders will prefer transfer 3.5 instead of 4 . Taking $N=2$, the payoff of each symmetrical bidder is equal to $\$ 2.60$ for $M=K=4$ and equal to $\$ 2.93$ for $M=3.5$, using the payment function $\pi=Z_{\mathrm{H}} q-C(q)+\left(P_{\mathrm{F}}-P_{\mathrm{I}}\right) q$ with $q=M / 2$, and the transfer cost function $C(q)=\frac{1}{2} q^{2}$. Note that, for $M=K=4, P_{\mathrm{F}}=3$, and for $M=3.5, P_{\mathrm{F}}=3.25$.

Example 2. Let a simple market model of a homogeneous agricultural product with functions of supply and demand in region 1 (region of origin) identical to those of Example 1. In region 2 (region of destination), demand is represented by the function $P=11-Q$ and supply is represented by the function $P=3+Q$, with equilibrium given by the ordered pair $\left(Q_{2}^{*}, P_{2}^{*}\right)=(4,7)$. At the intervention price $P_{\mathrm{I}}=4$, excess supply in region 1 is equal to 4 and excess demand in region 2 is equal to 6 . In this case, all the excess supply of region 1 is transferred to the region 2 and the maximum payoff that the symmetrical bidder gets is equal to $\$ 11.00$, if you consider the same parameters of Example 1, i.e., $N=2$, payoff function $\pi=Z_{\mathrm{H}} q-C(q)+\left(P_{\mathrm{F}}-P_{\mathrm{I}}\right) q$ with $q=M / 2$, and transfer cost function $C(q)=\frac{1}{2} q^{2}$. Note that, for $M=4, P_{\mathrm{F}}=5$.

Figure 2 shows the results of item (ii) of the Proposition 2. The intersection between the aggregate transfer curve $T_{3}$ and the fixed demand curve $M, 0<M<K$ generates the equilibrium $\left(Z_{\mathrm{H}}, M\right)$, and the intersection between the aggregate transfer curve $T_{2}$ and the fixed demand curve $K$ generates the 
Figure 2. Illustration of the results of item (ii) of the Proposition 2.

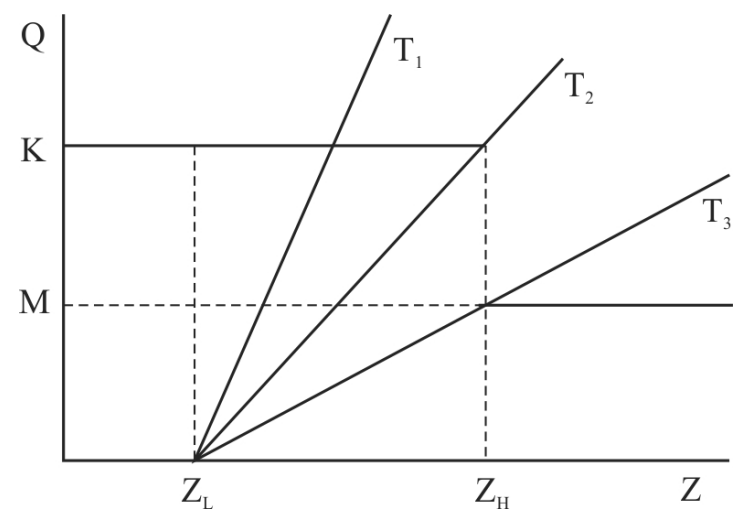

equilibrium $\left(Z_{\mathrm{H}}, K\right)$. Both results are commonly observed in public auctions of the PEP implemented by the CONAB, i.e., the auction ends immediately at the maximum prize when the sum of the amounts demanded by the winning bidders is lower or equal to the total amount of the agricultural product made available by the government for transfer between regions.

Item (i) of the Proposition 2 explains another result that has emerged from the auctions of the PEP, i.e., the auction is announced but is not effectively implemented due to the absence of interested bidders. In item (i) of the Proposition 2, we claim that bidders will not participate in auctions if they are not offered opportunities of gains. The decision about whether they will participate or not in an auction is taken by potential bidders when they compare their marginal cost on product transfer between regions with the maximum prize (subsidy) announced by the government. Whenever the maximum prize is lower than the marginal cost for transfer of products between regions, no one will be interested in participating in the auction.

Another possible result for the descending clock auction is close to perfect competition, when bidders compete for transferring a product from the region of origin to the region of destination and accept a prize $Z$ such that $Z_{\mathrm{L}} \leq C^{\prime}(q)<Z<Z_{\mathrm{H}}$, i.e., bidders accept a prize close to the marginal cost of transfer. This result, which has been observed in some auctions of the PEP, is represented in Figure 2, for example, by the point where the aggregate transfer curve $T_{1}$ intercepts the fixed demand curve $K$. It may be explained by both the type of bidders participating in the auction and the excess demand greater than excess supply at the intervention price. Bidders who are not wholesalers and use agricultural products as a raw material in agro-industrial processing will be less likely to behave strategically in an auction when compared to a typical wholesaler. Their main interest is to purchase agricultural raw material at the minimum price set by the government, which may be achieved through participation in auctions. The Brazilian government itself has directed some auctions of the PEP for bidders who are non-wholesalers and use agricultural products in the region of destination for agro-processing.

In announcing the auction, suppose now that the government tells the maximum prize and the maximum amount to be transferred of the agricultural product from the region of origin to the destination region without imposing a minimum amount to be transferred (Assumption 2). The decision on the total amount to be transferred between regions would be taken by the bidders through the choice of their strategies. This situation occurs frequently in the auctions of the PEP implemented by the Brazilian government. We can take this into account and extending the result of part (ii) of Proposition 2 in the following corollary.

Corollary. Suppose that a descending clock auction with maximum fixed demand $K>0$ and finite maximum prize $\left(Z_{H}>0\right)$ is implemented with any number of bidders and that excess supply (equal to $K$ ) in the region of origin is greater than excess demand in the region of destination at the intervention price $\left(P_{\mathrm{I}}\right)$. If the auction rule 
allows transferring any quantity $M, 0 \leq M \leq K$, then the strategy $q\left(Z_{H}\right)=\max \left\{\pi_{M}=Z_{H} q-C(q)+\left(P_{F}-P_{I}\right) q\right.$ : $0 \leq M \leq K\}$ is a symmetric Nash equilibrium of the descending clock auction game.

Proof. Note that the maximization problem has a solution because the objective function (payoff function) is continuous and the constraint set, $M \in[0, K]$, is compact. This solution is obtained by solving the following nonlinear programming problem: $\max \pi_{M}$ subject to $0 \leq M \leq K$; i.e., maximizing the following Lagrangian function: $L=Z_{\mathrm{H}}\left(\frac{M}{N}\right)-C\left(\frac{M}{N}\right)+\left(P_{\mathrm{F}}(M)-P_{\mathrm{I}}\right)\left(\frac{M}{N}\right)+\lambda(K-M)$, where $q=M / N$ and $\lambda$ is the Lagrange multiplier. The solution of this problem provides the amount $M^{*}$ to be transferred between regions since the transfer cost functions, and the functions of supply and demand of the destination region for the calculation of the final price $\left(P_{\mathrm{F}}\right)$ are known.

Using information from Example 1 and proceeding according to the above Corollary, we obtain $M^{*}=$ 2.87 as the quantity to be transferred from the region of origin to the region of destination. In this case, the gain of each symmetrical bidder equals \$3.08, higher than those calculated in Example 1 for $M=3.5$ and $M=4$. The transfer of $M^{*}=2.87$ from region 1 to the region 2 will reduce the equilibrium price in the region 2 from 5 to 3.57, i.e., a value lower than the intervention price which is equal to 4 . Note that the transfer of $M^{*}=2.87$ between regions, although optimal from the standpoint of bidders is not the most appropriate from the point of view of implementing the minimum price policy, since a region with excess demand turns in a region with excess supply.

The results obtained in this article, especially those of Proposition 2 and its Corollary, and the data available on the auctions of the PEP already held, provide insights that may be useful to minimize the costs of the Brazilian government in the implementation of a policy of minimum prices via auctions. The first one concerns the two basic auction parameters: the amount of agricultural product made available for auctioning and the maximum prize (subsidy). The amount of agricultural product made available for being auctioned must be based on accurate estimates of excesses supply and demand of key regions at the minimum price set by the government. The auction of amounts inconsistent with the excesses of supply and demand of regions may seriously compromise the effective implementation of the minimum price policy, thus increasing its costs. Maximum prizes, as already pointed out, should cover at least the marginal cost of product transfer between regions and eventually provide a small margin gains for bidders. Maximum prizes well above the marginal transfer cost may increase the costs of implementing the minimum price policy due to the strategic behavior of the bidders who will try to maximize their gains.

If the government does not have accurate estimates of excess supply and excess demand between regions at the reference price (minimum price), it should hold more than one auction to observe the behavior of prices of agricultural products in the regions of origin and destination and infer about the need for implementing new auctions. The Brazilian government already does this, i.e., it implements several auctions usually between intervals of one week. It is recommended, in this case, the implementation of few auctions (no more than two or three) and the entire amount made available for auctioning must be purchased by bidders for transfer between regions. The government should prohibit the purchase of amounts smaller than those allocated for transfer between regions; otherwise, as observed in item (ii) of Proposition 2 and its Corollary, the bidders can take advantage of it, which would lead to increased costs of implementing the minimum price policy. Finally, products with large numbers of producers and sellers tend to attract more participants to the auctions and, with this, increase the chance of bidders being more aggressive in their bids. At the starting of the auction, it is desirable to get a situation of excess demand greater than excess supply such that the competition between bidders leads to the reduction of the initial prize announced by the government in advance.

\section{CONCLUDING COMMENTS}

In this article we analyzed the use of auctions in implementing a minimum price policy. This analysis was based on the implications of a theoretical descending clock auction model and on data available 
from auctions of this kind implemented by the Brazilian government in its Program for Product Flow (Prêmio para Escoamento de Produto, PEP). The Brazilian policy of supporting agricultural prices is based on a system of guaranteed minimum prices and public auctions implemented by the government are important mechanisms for implementing this policy.

The results of the analysis developed in this article allow recommending the following actions in order to minimize the expenses in implementing that policy via auctions. First, the maximum prize (subsidy) must be defined in such a way to cover the marginal costs of agricultural product transfer between regions and, eventually, provide some margin gains to bidders in order to encourage participation and/or competition between them; maximum premiums well above the marginal cost of transfer increase the costs of implementing the minimum price policy due to the strategic behavior of the bidders who try to maximize their gains. Second, the amount of agricultural product made available by the government in announcing the auction must be based on accurate estimates of excess supply and excess demand of key regions at the intervention price; auction quantities inconsistent with these excesses of supply and demand can undermine the effective implementation of the minimum price policy and, consequently, increase its costs. Third, the government should prioritize the destination region when setting the amount of product to be transferred between regions; with this, it is possible to restrict the scope for bidders' gains by not allowing them to auction quantities below to that offered by the government. Finally, agricultural products with large numbers of buyers and sellers tend to attract more participants to the auctions and, therefore, increase the chances of competition for products auctioned.

The analysis developed in this article focused on two regions: region of origin and region of destination. This analysis can be extended to consider a region of origin and several destination regions or several regions of origin and several destination regions. A general equilibrium approach would be necessary to estimate accurately the excesses of supply and demand of key regions at the minimum price set by the government. With this information, the key parameters of the auctions would be more easily defined, i.e., maximum premiums (subsidies) and amounts to be auctioned between pairs of regions. A broad program with use of auctions could then be used to implement a minimum pricing policy.

\section{REFERENCES}

Ajayi, O. C., Jack, B. K., \& Leimona, B. (2012). Auction design for the private provision of public goods in developing countries: Lessons from payments for environmental services in Malawi and Indonesia. World Development, 40(6), 1213-1223. doi: 10.1016/j.worlddev.2011.12.007

Ausubel, L. M., \& Schwartz, J. A. (1999). The ascending auction paradox. Retrieved from http://www.marketdesign .com/files/ausubel-schwartz-ascending-auction-paradox.pdf

Bel Filho, E. D., \& Bacha, C. J. C. (2005). Avaliação das mudanças na política de garantia de preços mínimos: Período de 1997 a 2004. Revista de Economia e Agronegócio, 3(1), 51-76. Retrieved from http://www.revistarea .ufv.br/index.php/rea/article/view/50

Betz, R., Seifert, S., Cramton, P., \& Kerr, S. (2010). Auctioning greenhouse gas emissions permits in Australia. Australian Journal of Agricultural and Resource Economics, 54(2), 219-238. doi: 10.1111/j.14678489.2010.00490.x

Cassady, R., Jr.. (1967). Auctions and auctioneering. Berkeley: University of California Press.

Ciarreta, A., \& Espinosa, M. P. (2010). Market power in the Spanish electricity auction. Journal of Regulatory Economics, 37(1), 42-69. doi: 10.1007/s11149-009-9102-7

CONAB. (2012). Resumo dos leilões da CONAB por ano - Resumo Anual de 2012. Retrieved October 2012, from http://www.conab.gov.br/conteudos.php?a $=1374 \& \mathrm{t}=2$

Cramton, P., \& Sujarittanonta, P. (2010). Pricing rule in a clock auction. Decision Analysis, 7(1), 40-57. doi: 10.1287/deca.1090.0161

Fabra, N., von der Fehr, N.-H., \& Harbord, D. (2006). Designing electricity auctions. The RAND Journal of Economics, 37(1), 23-46. doi: 10.1111/j.1756-2171.2006.tb00002.x 
Grimm, V., Riedel, F., \& Wolfstetter, E. (2003). Low price equilibrium in multi-unit auctions: The GSM spectrum auction in Germany. International Journal of Industrial Organization, 21(10), 1557-1569.

Latacz-Lohmann, U., \& Van der Hamsvoort, C. (1997). Auctioning conservation contracts: A theoretical analysis and an application. American Journal of Agricultural Economics, 79(2), 407-418. doi: 10.2307/1244139

Milgrom, P. (2004). Putting auction theory to work. New York: Cambridge University Press.

Osborne, M. J., \& Rubinstein, A. (1994). A course in game theory. Cambridge, MA: The MIT Press.

Pereira, M. W. G., \& Vieira, W. d. C. (2009). Análise da política de garantia de preços mínimos: 0 caso do Prêmio para Escoamento do Produto. Revista de Política Agrícola, 18(2), 6-17. Retrieved from https://seer.sede .embrapa.br/index.php/RPA/article/view/368

Sunnevåg, K. J. (2003). Auction design for the allocation of emission permits in the presence of market power. Environmental and Resource Economics, 26(3), 385-400. doi: 10.1023/B\%3AEARE.0000003583.49609.c7 